\title{
EXCESS MOLAR VOLUMES, AND REFRACTIVE INDEX OF BINARY MIXTURES OF GLYCEROL + METHANOL AND GLYCEROL + WATER AT 298.15 K AND 303.15 K
}

\author{
Ufuk Sancar Vural $^{1}$, V. Muradoglu ${ }^{2^{*}}$ and Sedat Vural ${ }^{3}$ \\ ${ }^{1}$ Department of Chemistry, Faculty of Arts \& Sciences, Selcuk University, 42079 Konya, Turkey \\ ${ }^{2}$ Department of Chemistry, Faculty of Arts \& Sciences, Nigde University, Nigde, Turkey \\ ${ }^{3}$ Ilgin Industry Occupation Highschool, Konya, Turkey
}

(Received July 22, 2009; revised December 1, 2010)

\begin{abstract}
Excess molar volumes $\left(\mathrm{V}^{\mathrm{E}}\right)$ viscosities and refractive index have been evaluated for binary mixtures of glycerol + water, and glycerol + methanol at $298.15 \mathrm{~K}$ and $303.15 \mathrm{~K}$. Excess molar volumes $\left(\mathrm{V}^{\mathrm{E}}\right)$ have been calculated from density. The excess molar volume $\left(\mathrm{V}^{\mathrm{E}}\right)$ results were fitted to the Redlich and Kister type polynomial equation to derive the binary coefficients and estimate the standard deviations between experimental and calculated results. It is observed that all mixtures show positive values of $\mathrm{V}^{\mathrm{E}}$ obviously due to increased physical interactions between glycerol and methanol, and water.
\end{abstract}

KEY WORDS: Excess molar, Density, Refractive index, Glycerol, Water, Methanol

\section{INTRODUCTION}

The price of fossil diesel is soaring in the recent years and it will be exhausted some day. Thus, looking for an alterative way to develop a substitute of diesel is an imperious task for humans. Biodiesel, defined as "a substitute for, or a additive to diesel fuel that is derived from the oils and fats of plants and animals" or mono-alkyl esters of long chain fatty acids derived from a renewable lipid feedstock, such as vegetable oil or animal fat, is becoming popular in the markets of developed countries as well as developing ones [1,2]. Glycerol is the important side product of biodiesel and used in many wide industrial applications. Glycerol can be obtained by transesterification reaction of vegetable oil or animal oil with any alcohol as a mixture of water, methanol, catalyst, and unreacted oil or fatty acids. Main compounds are methanol and water in this glycerol mixture.

The physical properties of binary mixtures are studied for many reasons, the most important of which is to provide information about molecular interactions present in the liquid state [3]. Experimental data of physical properties such of densities, viscosities, or refractive indices are required for a full understanding of the thermodynamic properties of liquid mixtures, as well as for practical chemical engineering work [4-8]. The studies of excess thermodynamic properties are of considerable interest in understanding the intermolecular interactions in binary liquid mixtures [9]. Knowledge of these properties is very important in many practical problems concerning mass transport and fluid flow.

In the present paper, we report excess molar volumes, viscosities and refractive index of binary mixtures of glycerol + water and glycerol + methanol covering the whole composition range and at $298.15 \mathrm{~K}$ and $303.15 \mathrm{~K}$.

*Corresponding author. E-mail: vmuradoglu@yahoo.com 


\section{EXPERIMENTAL}

\section{Materials}

To prepare biodiesel by basic catalysed transesterification, refined soy oil was obtained from general store. The free fatty acid content of the oil was determined as $0.1 \%$ according to the titrimetric method. Certified methanol of $99.8 \%$ purity, the catalysts (sodium hydroxide), benzene, and toluene were purchased from Merck Chemical Co. The purities of these substances are more than 99\%. All reagents were used without further purification. The measured densities and viscosities of the pure components at $298.15 \mathrm{~K}$ were compared with the literature values, and the result is presented in Table 1.

Table 1. Experimental density, dynamic viscosity, and refractive index of compounds, and comparison with literature [10].

\begin{tabular}{|l|c|c|c|c|}
\hline Compound & Experimental $\left(20^{\circ} \mathrm{C}\right)$ & & Literature $\left(20^{\circ} \mathrm{C}\right)$ & \\
\hline & $\rho(\mathrm{g} / \mathrm{mL})$ & $\mathrm{n}_{\mathrm{D}}{ }^{20}$ & $\rho(\mathrm{g} / \mathrm{mL})$ & $\mathrm{n}_{\mathrm{D}}{ }^{20}$ \\
\hline Methanol & 0.7918 & 1.3289 & 0.7866 & 1.3282 \\
\hline Water & 0.9981 & 1.3336 & 0.9970 & 1.3334 \\
\hline Glycerol & 1.2619 & 1.4730 & 1.2614 & 1.4729 \\
\hline
\end{tabular}

Glycerol production

The reactions have been carried out at $65.0^{\circ} \mathrm{C}$ with a $6: 1$ molar ratio of methanol to oil and $1 \%$ of basic catalyst by weight of vegetable oil in a $100 \mathrm{~mL}$ three-necked batch reactor equipped with a reflux condenser, a mechanical stirrer and a stopper to remove samples [2]. The impeller was set at $600 \mathrm{rpm}$ to avoid mass transfer limitations on the process. This reactor was immersed in a constant-temperature bath, which was capable of maintaining the reaction temperature to within $\pm 0.1^{\circ} \mathrm{C}$ of the intended figure. In turn, each experiment was repeated three times to evaluate the experimental errors.

The reactor was initially charged with the desired amount of oil $(60 \mathrm{~g})$, then placed in the constant temperature bath with its associated equipment and heated to a predetermined temperature. The catalyst was dissolved in the methanol and the resulting solution was added to the agitated reactor. The reaction was timed as soon as the catalyst/methanol solution was added to the reactor and it continued for $2 \mathrm{~h}$. The mixture was transferred to a separation funnel, allowing glycerol to separate by gravity for $12 \mathrm{~h}$. After removing the glycerol layer, the methanol was recovered by distillation and glycerol was obtained by vacuum distillation at $190.0{ }^{\circ} \mathrm{C}, 0.01 \mathrm{mmHg}$ vacuum pressures.

Density and refractive index measurements of pure and binary mixtures

Each sample mixture was prepared, on mass basis, by mixing the calculated volumes of liquid components in specially designed glass stopper bottles. The mass measurements $\pm 0.0001 \mathrm{~g}$ were made using an electronic balance with an accuracy of $0.1 \mathrm{mg}$. A set of twenty compositions was prepared for each system, and their densities and absolute viscosities were measured on the same time. Densities of the pure components and their compositions were measured on a vibrating tube densitymeter, which was reproducible to $1 \times 10^{-4} \mathrm{~g} / \mathrm{mL}$ (Anton Paar Model DMA $35 \mathrm{~N})$. This unit offered high temperature accuracy $( \pm 0.001 \mathrm{~K})$ in a wide temperature range. Calibration of the densitymeter was done with triple distilled water, showing density 0.9982 $\mathrm{g} / \mathrm{mL}$ at $20^{\circ} \mathrm{C}$ which is close to literature value [10]. The mixtures were prepared by mixing 
known masses of pure liquids in air tight, narrow-mouth ground stopper bottles taking due precautions to minimise evaporation losses. All measurements of mass were performed on an electronic balance with an accuracy of $0.1 \mathrm{mg}$.

The refractive indices were measured with a thermostated Abbe refractometer with reproducibility in the refractive index data of $10^{-4}$. Finally, mixtures were prepared in all cases by an electronic balance with an accuracy of $0.1 \mathrm{mg}$.

\section{RESULTS AND DISCUSSION}

\section{Excess molar volume}

The excess molar volumes $\mathrm{V}^{\mathrm{E}}$ over the entire composition range for binary mixtures of (x)glycerol + (1-x)methanol, or (1-x) water were calculated from density data at the temperature $\mathrm{T}=298.15 \mathrm{~K}$ and $303.15 \mathrm{~K}$ and atmospheric pressure. The densities, excess molar volumes on mixing are listed in Table 2.

Table 2. The density and excess molar volumes of the binary mixtures of glycerol + methanol and glycerol + water at 298.15 , and $303.15 \mathrm{~K}$.

\begin{tabular}{|c|c|c|c|c|c|c|c|c|}
\hline & \multicolumn{4}{|c|}{ Methanol } & \multicolumn{4}{c|}{ Water } \\
\cline { 2 - 9 } & \multicolumn{2}{|c|}{$\rho(\mathrm{g} / \mathrm{mL})$} & \multicolumn{2}{|c|}{$\mathrm{V}^{\mathrm{E}}\left(\mathrm{mL} . \mathrm{mol}^{-1)}\right.$} & \multicolumn{2}{c|}{$\rho(\mathrm{g} / \mathrm{mL})$} & \multicolumn{2}{c|}{$\mathrm{V}^{\mathrm{E}}\left(\mathrm{mL} . \mathrm{mol}^{-1)}\right.$} \\
\hline $\mathrm{X}$ & $298.15 \mathrm{~K}$ & $303.15 \mathrm{~K}$ & $298.15 \mathrm{~K}$ & $303.15 \mathrm{~K}$ & $298.15 \mathrm{~K}$ & $303.15 \mathrm{~K}$ & $298.15 \mathrm{~K}$ & $303.15 \mathrm{~K}$ \\
\hline 0.00 & 1.2569 & 1.2527 & 0.0000 & 0.0000 & 1.2569 & 1.2527 & 0.0000 & 0.0000 \\
\hline 0.05 & 1.2319 & 1.2275 & 0.2954 & 0.2852 & 1.2495 & 1.2373 & 0.5576 & 0.5524 \\
\hline 0.10 & 1.2059 & 1.2005 & 0.5807 & 0.5616 & 1.2419 & 1.2308 & 1.0680 & 1.0578 \\
\hline 0.15 & 1.1733 & 1.1613 & 0.8535 & 0.8269 & 1.2283 & 1.2176 & 1.5296 & 1.5147 \\
\hline 0.20 & 1.1467 & 1.1389 & 1.1116 & 1.0786 & 1.2136 & 1.2106 & 1.9408 & 1.9215 \\
\hline 0.25 & 1.1383 & 1.1325 & 1.3521 & 1.3141 & 1.1965 & 1.1927 & 2.2999 & 2.2765 \\
\hline 0.30 & 1.1301 & 1.1284 & 1.5722 & 1.5303 & 1.1845 & 1.1816 & 2.6050 & 2.5781 \\
\hline 0.35 & 1.1138 & 1.1095 & 1.7688 & 1.7241 & 1.1694 & 1.1648 & 2.8545 & 2.8244 \\
\hline 0.40 & 1.0944 & 1.0904 & 1.9386 & 1.8922 & 1.1553 & 1.1520 & 3.0462 & 3.0135 \\
\hline 0.45 & 1.0717 & 1.0686 & 2.0777 & 2.0308 & 1.1448 & 1.1392 & 3.1782 & 3.1434 \\
\hline 0.50 & 1.0559 & 1.0504 & 2.1822 & 2.1358 & 1.1321 & 1.1295 & 3.2484 & 3.2122 \\
\hline 0.55 & 1.0283 & 1.0236 & 2.2475 & 2.2025 & 1.1212 & 1.1176 & 3.2546 & 3.2175 \\
\hline 0.60 & 1.0066 & 1.0014 & 2.2685 & 2.2259 & 1.1011 & 1.0987 & 3.1943 & 3.1572 \\
\hline 0.65 & 0.9874 & 0.9837 & 2.2398 & 2.2004 & 1.0989 & 1.0942 & 3.0652 & 3.0289 \\
\hline 0.70 & 0.9632 & 0.9600 & 2.1550 & 2.1196 & 1.0748 & 1.0728 & 2.8646 & 2.8301 \\
\hline 0.75 & 0.9464 & 0.9428 & 2.0071 & 1.9765 & 1.0638 & 1.0596 & 2.5900 & 2.5581 \\
\hline 0.80 & 0.9273 & 0.9236 & 1.7881 & 1.7630 & 1.0476 & 1.0454 & 2.2383 & 2.2102 \\
\hline 0.85 & 0.9031 & 0.8993 & 1.4891 & 1.4698 & 1.0362 & 1.0324 & 1.8068 & 1.7836 \\
\hline 0.90 & 0.8822 & 0.8779 & 1.0996 & 1.0866 & 1.0183 & 1.0153 & 1.2921 & 1.2752 \\
\hline 0.95 & 0.8360 & 0.8302 & 0.6078 & 0.6013 & 1.0099 & 1.0068 & 0.6910 & 0.6817 \\
\hline 1.00 & 0.7859 & 0.7821 & 0.0000 & 0.0000 & 0.9970 & 0.9956 & 0.0000 & 0.0000 \\
\hline & & & & & & & & \\
\hline
\end{tabular}

The excess molar volumes of the binary mixtures, shown in Figure 1 and Figure 2, were computed from the density measurements by using the following equation [11]:

$$
V^{E}=\sum_{i=1}^{N} x_{i} M_{i}\left(\rho^{-1}-\rho_{i}^{-1}\right)
$$

where $\rho$ is the density of the mixture, $\rho_{i}$ is the density of pure component $i, x_{i}$ is the mole fraction, $\mathrm{M}_{\mathrm{i}}$ is the molar mass of component $\mathrm{i}$, and $\mathrm{N}$ stands for the number of components in 
the mixture. Excess molar volumes on mixing of the binary systems were fitted to RedlichKister [12,13] polynomials of the form:

$$
V^{E} /\left(m L m o l^{-1}\right)=x(1-x) \sum_{i=1}^{J} A_{i}\left(1-2 x_{i}\right)^{i}
$$

where $\mathrm{x}_{\mathrm{i}}$ is the mole fraction of glycerol, $\mathrm{A}_{\mathrm{i}}$ are adjustable parameters obtained by a leastsquares method, and $J$ is the degree of the polynomials. The coefficients $A_{i}$ were obtained by fitting Equation (2) to the experimental results using a least-squares regression method with all points weighted equally. In each case, the optimum number of coefficients is ascertained from the examination of the variation in the standard deviation, $\sigma\left(\mathrm{V}^{\mathrm{E}}\right)$. For none of the systems does the precision warrant the use of more than four parameters. The parameters $A_{0}, A_{1}, A_{2}, A_{3}$, and the extremum values of excess molar volume for each of binary mixtures are shown in Table 3 , along with the standard deviations $\sigma\left(\mathrm{V}^{\mathrm{E}}\right)$. The $\sigma\left(\mathrm{V}^{\mathrm{E}}\right)$ was calculated using Equation (3):

$$
\sigma\left(\mathrm{V}^{\mathrm{E}}\right)=\left[\sum_{i=1}^{n} \frac{V^{E}(c a l, i)-V^{E}(\exp , i)}{n-j}\right]^{1 / 2}
$$

where $\mathrm{n}$ is the number of experimental data, and $\mathrm{j}$ is the number of coefficients.

Table 3. Redlich-Kister equation parameters of the binary mixtures of glycerol + methanol, and + water at

\begin{tabular}{|c|c|c|c|c|}
\hline \multirow[b]{2}{*}{ Parameter } & $298.15 \mathrm{~K}$ & & $303.15 \mathrm{~K}$ & \\
\hline & Value & Std error & Value & Std error \\
\hline \multicolumn{5}{|c|}{ Excess molar volume } \\
\hline \multicolumn{5}{|c|}{ Methanol } \\
\hline $\mathrm{A}_{0}$ & $0.342 \times 10^{-1}$ & $0.691 \times 10^{-1}$ & $0.346 \times 10^{-1}$ & $0.676 \times 10^{-1}$ \\
\hline $\mathrm{A}_{1}$ & $6.518 \times 10^{-1}$ & $1.571 \times 10^{-1}$ & $6.382 \times 10^{-1}$ & $1.538 \times 10^{-1}$ \\
\hline $\mathrm{A}_{2}$ & $2.792 \times 10^{-1}$ & $1.778 \times 10^{-1}$ & $2.863 \times 10^{-1}$ & $1.740 \times 10^{-1}$ \\
\hline$A_{3}$ & $-8.382 \times 10^{-1}$ & $3.182 \times 10^{-1}$ & $-8.203 \times 10^{-1}$ & $3.114 \times 10^{-1}$ \\
\hline \multicolumn{5}{|c|}{ Water } \\
\hline $\mathrm{A}_{0}$ & $15.42 \times 10^{-3}$ & $1.029 \times 10^{-1}$ & $0.1496 \times 10^{-1}$ & $1.018 \times 10^{-1}$ \\
\hline $\mathrm{A}_{1}$ & $95.88 \times 10^{-2}$ & $2.339 \times 10^{-1}$ & $9.480 \times 10^{-1}$ & $2.312 \times 10^{-1}$ \\
\hline $\mathrm{A}_{2}$ & $21.99 \times 10^{-3}$ & $2.647 \times 10^{-1}$ & $0.204 \times 10^{-3}$ & $2.617 \times 10^{-1}$ \\
\hline $\mathrm{A}_{3}$ & $-12.49 \times 10^{-2}$ & $4.736 \times 10^{-1}$ & $-0.123 \times 10^{1}$ & $4.683 \times 10^{-1}$ \\
\hline \multicolumn{5}{|c|}{ Excess molar refractive index } \\
\hline $\mathrm{A}_{0}$ & $1.449 \times 10^{-1}$ & $4.468 \times 10^{-2}$ & $1.529 \times 10^{-8}$ & $4.657 \times 10^{-2}$ \\
\hline$A_{1}$ & $4.153 \times 10^{-1}$ & $1.0515 \times 10^{-1}$ & $4.332 \times 10^{-1}$ & $1.058 \times 10^{-1}$ \\
\hline $\mathrm{A}_{2}$ & $-3.722 \times 10^{-8}$ & $1.149 \times 10^{-1}$ & $-3.942 \times 10^{-8}$ & $1.198 \times 10^{-1}$ \\
\hline $\mathrm{A}_{3}$ & $-5.420 \times 10^{-1}$ & $2.056 \times 10^{-1}$ & $-5.654 \times 10^{-1}$ & $2.143 \times 10^{-1}$ \\
\hline \multicolumn{5}{|c|}{ Water } \\
\hline $\mathrm{A}_{0}$ & $1.191 \times 10^{-9}$ & $3.644 \times 10^{-3}$ & $3.887 \times 10^{-10}$ & $1.188 \times 10^{-3}$ \\
\hline $\mathrm{A}_{1}$ & $3.388 \times 10^{-2}$ & $8.279 \times 10^{-3}$ & $1.105 \times 10^{-2}$ & $2.700 \times 10^{-3}$ \\
\hline $\mathrm{A}_{2}$ & $-3.066 \times 10^{-9}$ & $9.370 \times 10^{-3}$ & $-1.000 \times 10^{-9}$ & $3.055 \times 10^{-3}$ \\
\hline $\mathrm{A}_{3}$ & $-4.421 \times 10^{-2}$ & $1.677 \times 10^{-2}$ & $-1.442 \times 10^{-2}$ & $5.468 \times 10^{-3}$ \\
\hline
\end{tabular}
298.15 and $303.15 \mathrm{~K}$.

In Figure 1 and 2, the excess molar volumes of the same mixtures at same temperatures are plotted against the mole fraction of biodiesel. In Figure 1 and Figure 2, the values of excess molar volume $\mathrm{V}^{\mathrm{E}}$ show a sigmoid kind of behaviour for the binary mixtures of glycerol with water and methanol. 


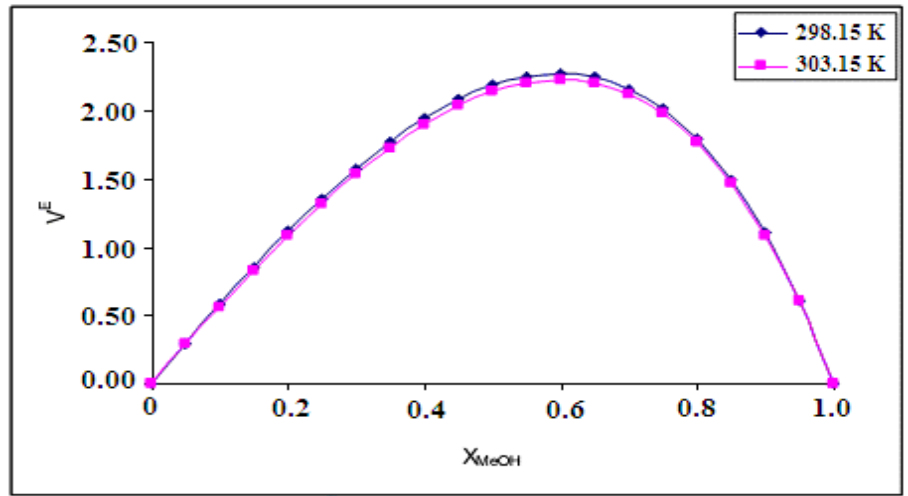

Figure 1. Excess molar changes of binary mixtures of glycerol + methanol at $298.15 \mathrm{~K}$ and $303.15 \mathrm{~K}$.

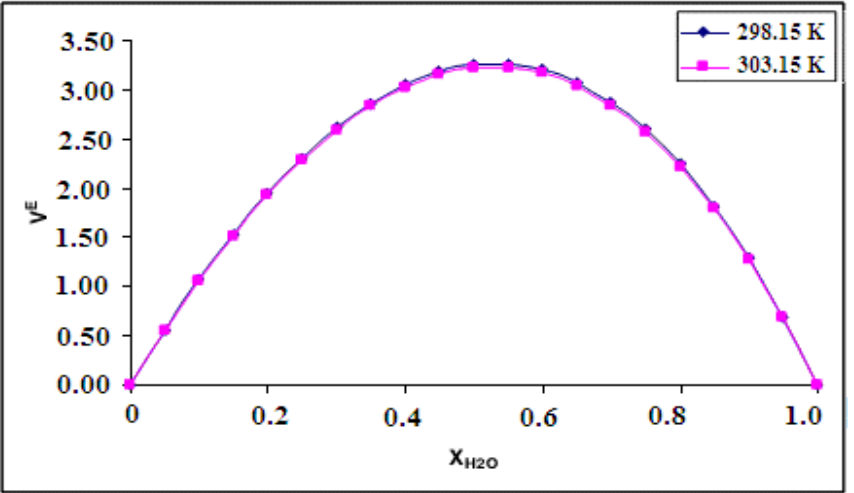

Figure 2. Excess molar changes of binary mixtures of glycerol + water at $298.15 \mathrm{~K}$ and 303.15 K.

$\mathrm{V}^{\mathrm{E}}$ is the resultant of contributions from several opposing effects [14]. These may be divided arbitrarily into three types, namely, chemical, physical, and structural. Physical contributions, which are non-specific interactions between the real species present in the mixture, contribute a positive term to $\mathrm{V}^{\mathrm{E}}$. The chemical or specific intermolecular interactions result in a volume decrease, and these include charge-transfer type forces and other complexforming interactions. This effect contributes negative values to $\mathrm{V}^{\mathrm{E}}$. The structural contributions are mostly negative and arise from several effects, especially from interstitial accommodation and changes of free volume. In other words, structural contributions arising from the geometrical fitting (interstitially accommodated) of one component into the other due to the differences in the free volume and molar volume between components lead to negative contribution to $\mathrm{V}^{\mathrm{E}}$.

The positive excess molar volume can be attributed to physical contributions, which are nonspecific interactions between the real species present in the mixture. The increase in excess molar volume with increasing dipole-dipole interactions are strong in higher hydrogen bonding 
of components [15], which is quite evident in the glycerol mixture with water and methanol. The same behaviour is obtained at $\mathrm{T}=303.15 \mathrm{~K}$, except that the values of $\mathrm{V}^{\mathrm{E}}$ become little positive causing the glycerol mixture to be positive over the entire composition range.

There is strong hydrogen bonding between hydroxyl group of glycerol. $\mathrm{V}^{\mathrm{E}}$ values decreases by order methanol < water in mixture. This order can be explained as: water molecules can attached to hydroxyl molecules of glycerol, and methanol molecules is more weak than water in this interaction. The hydrogen bonding is stronger between water molecules and glycerol than between hydroxyl molecules of glycerol or methanol + glycerol interaction.

Excess molar volumes are also arranged as water $>$ methanol at high temperature. This is because (a) water molecules have hydroxyl group which can make stronger hydrogen bonding than methanol and (b) water molecules and glycerol have suitable kinetic energy for bulk volumes at high temperature. Thus, the mixture of glycerol + water have big excess molar volume than methanol.

The hydrogen bonding between molecules of glycerol and methanol or water cover molecular interaction, such as charge-transfer complexes. Thus the hydrogen bonding or physical interaction is very clear in these interactions.

There are physical forces (hydrogen bonding) between glycerol and methanol, and water at binary mixtures. Even though the molecules are polar the chemical forces are weaker than physical forces. The positive value of excess volume, $\mathrm{V}^{\mathrm{E}}$, over the whole composition range suggesting the strong hydrogen bonding intermolecular interaction, For the system consisting of a hydrogen bonding as intermolecular interaction, the contraction in the volume on mixing is considered to occur by the component molecule with the smaller free volume making use of the larger free volume of the other component molecule.

\section{Excess molar refractive index}

The variation of the refractive indices on mixing with the mole fraction of glycerol (1) at $\mathrm{T}=$ 298.15 K and $\mathrm{T}=303.15 \mathrm{~K}$ is shown in Figure 3 and Figure 4, respectively. In Figure 3 and Figure 4, it can be seen that the changes in refractive index of glycerol mixtures with methanol and water are positive throughout the entire composition range, and that as the hydrogen bonding of the interaction increases the change in the refractive index becomes more negative.

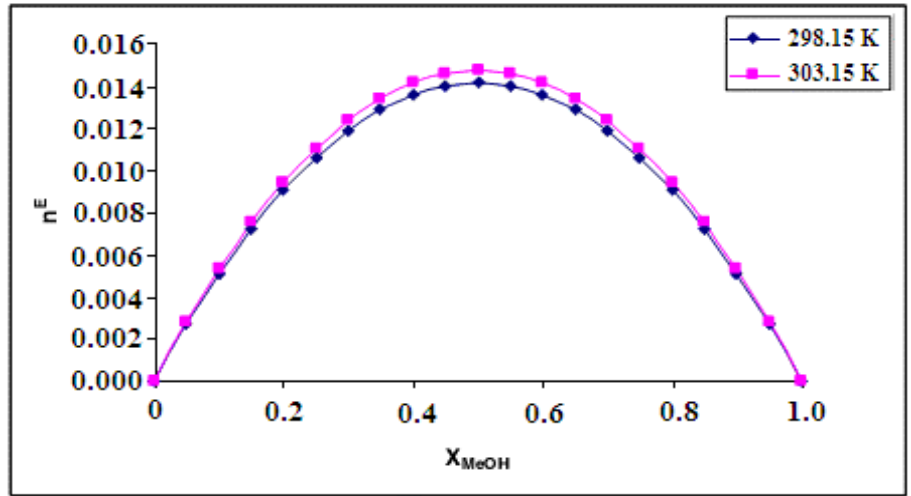

Figure 3. Excess molar refractive index of binary mixtures of glycerol + methanol at $298.15 \mathrm{~K}$ and $303.15 \mathrm{~K}$. 


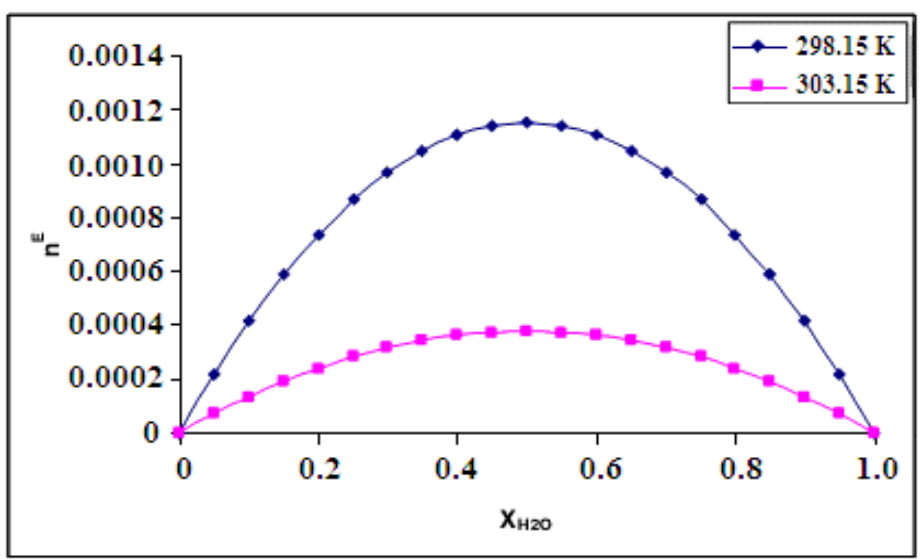

Figure 4. Excess molar refractive indexes of binary mixtures of glycerol + water at $298.15 \mathrm{~K}$ and $303.15 \mathrm{~K}$.

Table 4. The refractive index and excess molar refractive indexes of the binary mixtures of glycerol + methanol and glycerol + water at 298.15, and 303.15 K.

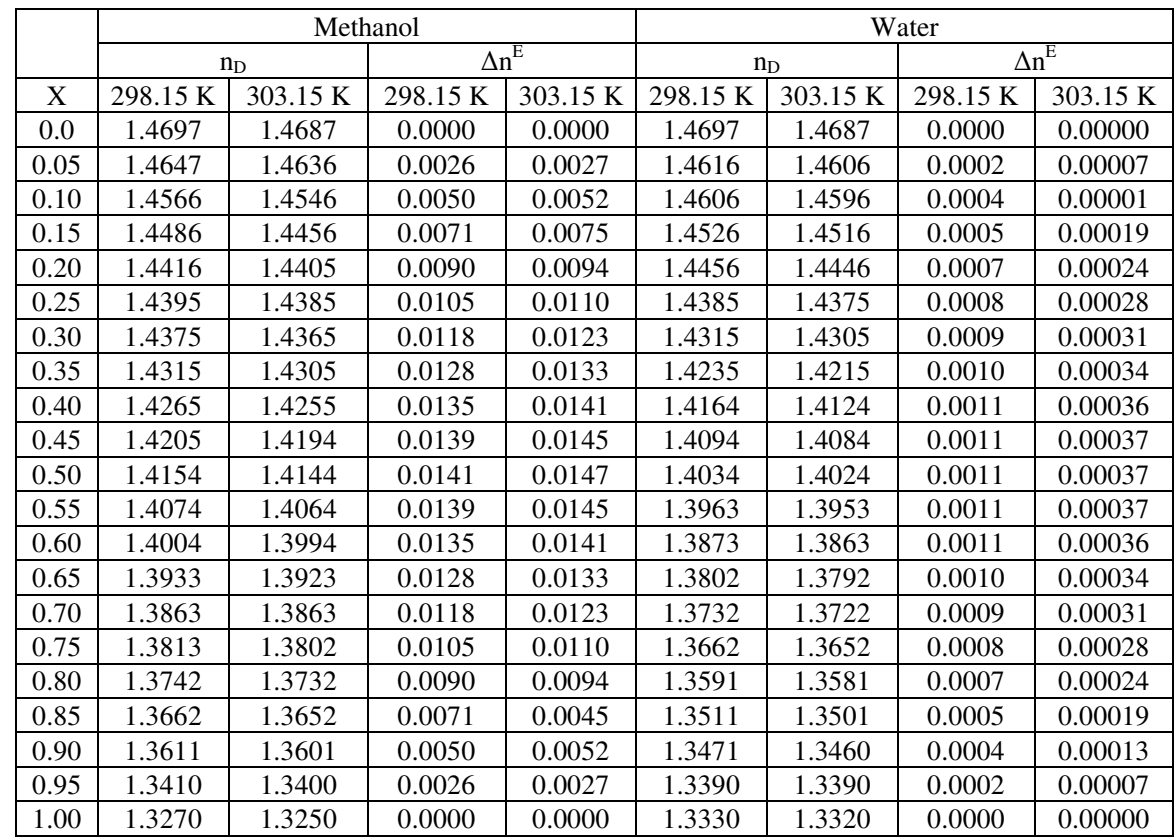

The experimental refractive indices of the binary mixtures were also compared with the values calculated using Equation (4). 


$$
\Delta n_{D}=\sum_{n \geq 0} a_{i}\left(x_{1}-x_{2}\right)^{i}
$$

where $n_{D}$ is the refractive index of the mixture. Deviations between the experimental and predicted refractive indices on mixing are listed in Table 4.

A satisfactory agreement is observed and the Lorentz-Lorenz model predictions were the closest to the experimental data of this work [16]. Overall, the deviations are less than 2 per cent for the studied binary mixtures.

It can be said about the change in refractive index of mixture of glycerol + water at $\mathrm{T}=$ $303.15 \mathrm{~K}$ which were slightly more positive than they were at $\mathrm{T}=293.15 \mathrm{~K}$. Refractive index values of mixture of glycerol + methanol are more big than mixture of glycerol+water. Because the strong hydrogen bonding of water + glycerol interaction cause to more weak bulk volume of methanol + glycerol.

\section{CONCLUSIONS}

This paper reports experimental data and excess molar properties of binary systems of the density and refractive index of glycerol + methanol (or water) at 298.15 , and $318.15 \mathrm{~K}$. Thermodynamic interactions in the binary mixtures have been studied in terms of a number of excess functions from the measured mixture properties. These functions are used to explain the physical forces as hydrogen bonding between mixture components. Excess molar properties can change with physical forces in polar molecules.

\section{ACKNOWLEDGEMENTS}

The authors thank Scientific Researches Council of Selcuk University for supporting this study.

\section{REFERENCES}

1. Mittelbach, M.; Trathnigg, B. Fat Sci. Technol. 1990, 92, 145.

2. Ma, F.; Hanna, M.A. Bioresour. Technol. 1999, 70, 1.

3. Ali, A.; Hyder, S.; Nain, A.K. J. Mol. Liq. 1999, 79, 89.

4. Francesconi, R.; Comelli, F.; Castellari, C. J. Chem. Eng. Data. 2000, 45, 544.

5. Vural, U.S.; Yuruk, H.; Muradoglu, V. Rus. J. Phys. Chem. 2003, 77, 1091.

6. Vural, U.S.; Muradoglu, V.; Yuruk, H. Rus. J. Phys. Chem. 2004, 78, 33.

7. Vural, U.S. Russ. J. Phys. Chem. 2005, 79, 1096.

8. Hind, A.H.; McLaughlin, E.; Ubbelohde, A.R. J. Chem. Soc. Faraday Trans. 1960, 56, 331.

9. Dominguez, M.; Pardo, J.; Lopez, M.C.; Royo, F.M.; Urieta, J.S. Fluid Phase Equilib. 1996, 124, 147.

10. TRC Tables, Thermodynamic Tables, Version 2.0, Thermodynamic Research Center, Houston, TX, 1995; Mori, H.; Iwata, J. J. Chem. Eng. Jpn. 1984, 37, 850.

11. Kermanpour, F.; Jahani, H.; Iloukhani, H. J. Mol. Liquids 2009, 146, 29.

12. Redlich, O.; Kister, A.T. Ind. Eng. Chem. 1948, 40, 345.

13. Iloukhani, H.; Almasi, M. Thermochim. Acta 2009, 495, 139.

14. Frenkel, I. Kinetic Theory of Liquids, Oxford University Press: London; 1946.

15. Fort, R.J.; Moore, W.R. Trans. Faraday Soc. 1965, 61, 2102.

16. Vijayalakshmi, T.S.; Naidu, P.R. J. Chem. Eng. Data 1992, 37, 368. 